\title{
Optimal Design for Rear Drive Axle House Based on Fuzzy Reliability Robust Analysis
}

\author{
Wu Zhijun \\ College of Mechanical and Electrical Engineering \\ Sichuan Agricultural University \\ Yaan, China \\ e-mail: wuzjhit@163.com
}

\author{
Zhang Lihua \\ College of Mechanical and Electrical Engineering \\ Sichuan Agricultural University \\ Yaan, China \\ Corresponding author e-mail: zhanglihua69@126.com
}

\begin{abstract}
In this paper, the rear drive axle house of Dong Fang Hong 40 tractor was selected as the research object, through Finite Element Analysis by ANSYS Workbench, critical sections and conditions were obtained. Based on results by FEA, multi-objective fuzzy reliability robustness design model of rear drive axle house was built. Applying genetic algorithm to solve the design model, multi-objective fuzzy reliability robustness design model was changed into several single-objective fuzzy reliability design models. Though adding the deflection constraint, static strength constraint, fatigue strength constraint, dimension constraint and fuzzy boundary condition constraint, the optimal design parameters were obtained. Compared with the original design, the mass of axis house was reduced by $20.54 \%$, the sensitivity was also cut down by $33.08 \%$, and the reliability and robustness were also improved. Combined with genetic algorithm, the fuzzy reliability robustness design method has obvious advantages than traditional methods, and the optimal results have been successfully applied.
\end{abstract}

Keywords-rear drive axle house; fuzzy reliability; robustness; genetic algorithm; tractor

\section{INTRODUCTION}

Rear drive axle house of tractor is the one of primary bearing members, bearing the weight of tractor with front axle. Rear drive axle house is used to support and protect the half axle, simultaneously transferring forces and torques from the wheel of tractor. Since the structure and shape are so complex, it's difficult to use the traditional method to carry on the accurate calculation. Wu and Sun have optimized the automobile axle through Finite Element Method (FEM), but just single target has been optimized. Zhang etc. have analyzed the rear axle through reliability robust optimization design, but the judgment of critical sections only depended on the experience of designer. In this paper, the rear drive axle house of Dong Fang Hong 40 tractor is selected as the research object, three-dimensional (3D) physical model of rear drive house is developed. Applying mechanics simulation on the 3D model based on ANSYS Workbench, the working conditions are obtained when the critical sections and maximum stress occur. Finally, using fuzzy reliability robustness design method to optimize the model, and solve it with genetic algorithm. The calculated results indicate that the method used in this paper is feasible.

\section{MECHANICAL MODEL}

\section{A. Mechanical Analysis of Rear Drive Axle House}

Under normal working conditions, the final drive house is connected with automobile body, the joint is considered as rigid connection. The rear drive axle house is hitched on the hollow crossrail of final drive house, fixed on the wheels through hub. The rear drive axle house is constrained by final drive house, simultaneously bears the ground force which is transferred by wheels. Compared with the overall mass of tractor, the mass of automobile body is relative small, which can be neglected. Thus, force acting on the supporting steel sheet by automobile body is considered as zero. The sketch of mechanical analysis is shown in Fig .1.

In Fig .1, 1 denotes final drive house of tractor, 2 denotes rear drive axle house, 3 is the rear drive axle, 4 is wheel, $R_{r}$ denotes wheel rolling radius, $b$ is the distance between center line of wheel and final drive house, $F_{x}, F_{y}$ and $F_{z}$ are lateral adhesion force, drive force and vertical force of wheel acting by ground respectively.

\section{B. Main Parameters of Rear Drive Axle House}

The rear drive axle house of Dong Fang Hong 40 tractor is selected as research object, the structural diagram is shown in Fig .2, and the corresponding parameters are given out in TABLE I.

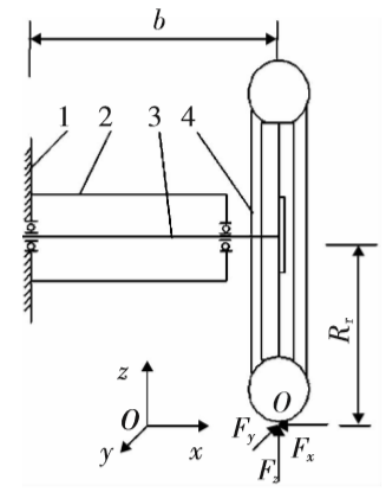

Figure 1. Sketch of mechanical analysis for rear drive axle house 


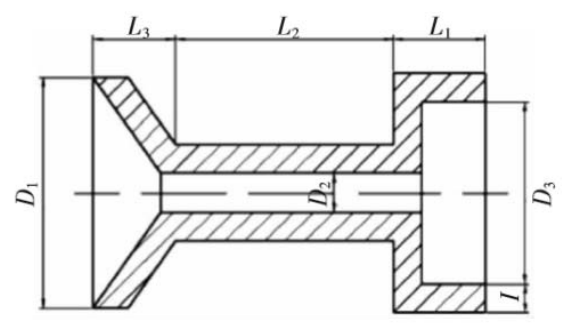

Figure 2. Structural diagram of rear drive axle house

TABLE I. THE CORRESPONIDNG PARAMETERS OF REAR DRIVE AXLE HOUSE

\begin{tabular}{|c|c|}
\hline Designation & Value (mm) \\
\hline L1 & 107 \\
\hline L2 & 285 \\
\hline L3 & 68 \\
\hline D1 & 236 \\
\hline D2 & 97 \\
\hline D3 & 216 \\
\hline I & 12 \\
\hline
\end{tabular}

The material strength of rear drive axle house $\omega$ is $\left(v_{r}, \sigma_{r}\right)=(443.5,27.5) \quad \mathrm{MPa}, \quad$ Elastic modulus $E=150 \mathrm{GPa}$, Poisson ratio $\mu=0.25$, the gravity distributed on the rear axle $G_{h}=14.06 \mathrm{kN}$, the lateral adhesion coefficient $\phi=0.65$.

\section{Strength Calculation of Rear Drive Axle House}

The force situations of rear drive axle house can be divided into three typical working conditions. If the strength of rear drive axle house under critical conditions is ensured, then reliability of the driving tractor under same conditions is ensured.

When driving tractor is on the uneven road, the bending stress of rear drive axle house at the position $\mathrm{x}$ which is the distance from center line of wheel

$$
\sigma_{x}=k M_{x} / W_{x}
$$

In (1), $M_{x}$ and $W_{x}$ are the bending moment and section modulus in bending of rear drive axle house at the section $\mathrm{x}$ respectively, $k$ is the dynamic load coefficient. For tractors, $k=2.5$.

When traction force reaches a maximum, rear drive axle house bears the combined effect of bending moment and torque. According to the fourth strength theory, the resultant stress of rear drive axle house at $\mathrm{x}$ is

$$
\sigma_{x}=\sqrt{S_{x}^{2}+3 \tau_{x}^{2}}=\sqrt{M_{x}^{2}+0.75 T_{x}^{2}} / W_{x} .
$$

In (2), $k=2.5$ is the torque of rear drive axle house at the section $x, S_{x}$ is the normal stress induced by bending moment, and $\tau_{x}$ is the shear stress induced by torque.

$$
\sigma_{x}=\sigma_{x 1}+\sigma_{x w}
$$

In (3), $\sigma_{x 1}$ and $\sigma_{x w}$ are tensile stress and bending stress caused by lateral force.

For tubular section of rear drive axle house, the section modulus in turning and bending at position $x$ can be calculated as follows:

$$
\begin{aligned}
& W_{\tau x}=\pi\left(D_{x}^{4}-d_{x}^{4}\right) / 16 D_{x} . \\
& W_{x}=\pi\left(D_{x}^{4}-d_{x}^{4}\right) / 32 D_{x} .
\end{aligned}
$$

In (4) and (5), $D_{x}$ is the external diameter at section $x, d_{x}$ is the internal diameter at section $x$.

\section{JUDGEMENT OF CRITICAL SECTIONS AND CONDITIONS}

Set up the 3D physical model of the rear drive axle house of Dong Fang Hong 40 tractor based on UG, and then input into ANSYS Workbench, finally carry out the mechanical analysis. The analytical results are shown in Fig .3, Fig .4 and Fig .5.

Simulation results based on FEM indicate that the critical section of rear drive axle house occurs at the juncture of small tube and big tube, which is $564 \mathrm{~mm}$ away from center line of wheel. The most critical condition achieves when the driving tractor is on uneven road, simultaneously the maximum stress is $154.42 \mathrm{MPa}$, which is obviously less than the allowable stress of material 443MPa. Thus, this paper mainly focuses on the optimized design of rear drive axle house when the most critical condition occurs.

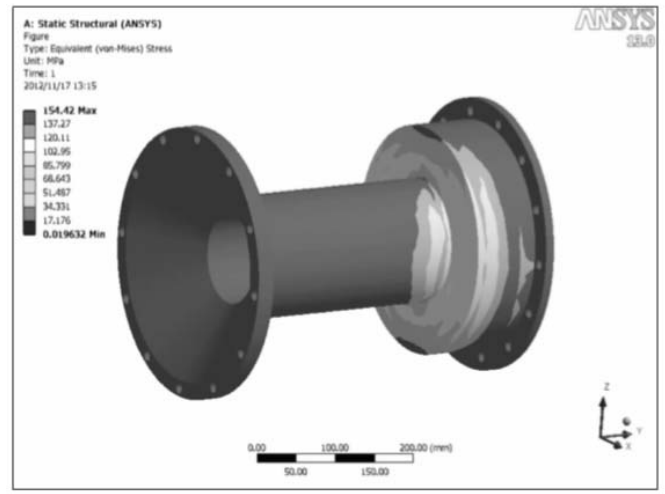

Figure 3. Mechanical analysis of rear drive axle house based on FEM when driving on uneven road

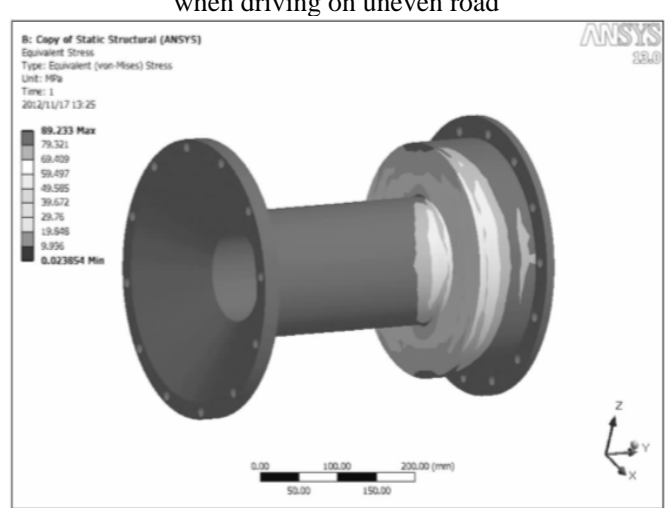

Figure 4. Mechanical analysis of rear drive axle house based on FEM when traction force reaches a maximum 


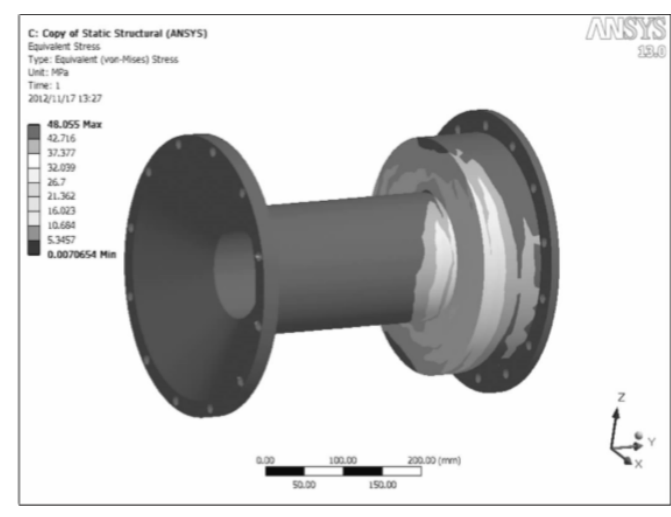

Figure 5. Mechanical analysis of rear drive axle house based on FEM when lateral force reaches a maximum

\section{FUZZY RELIABILITY ROBUSTNESS OPTIMIZTED DESIGN FOR REAR DRIVE AXLE HOUSE}

\section{A. Fuzzy Reliability Function of Rear Drive Axle House}

The fuzzy state describes the transient process of rear drive axle house from safety state to failure state. The safety state function of rear drive axle house $y$ is defined:

$$
y=y_{s}-y_{l} \text {. }
$$

In (6), $y_{s}$ and $y_{l}$ are the strength and stress of rear drive axle house respectively.

Supposed that the safety state of rear drive axle house is a fuzzy event $A$, and then the reliability of $A$ is calculated as:

$$
R=P(\underset{\sim}{A})=\int_{-\infty}^{+\infty} \mu_{\sim}(y) f(y) d y
$$

In (7), $y$ is safety state function of rear drive axle house, $\mu_{A}(y)$ is the membership function of $A$, and $f(y)$ is the fuzzy reliable probability density function.

The membership function depends on the fuzzy statistical method used. According to Ref.6, membership function uses rising semi-parabolic distribution in this paper, its mathematical expression:

$$
\mu_{\sim}(y)= \begin{cases}0 & (y \leq a) \\ \left(\frac{y-a}{b-a}\right)^{2} & (a<y \leq b) . \\ 1 & (y>b)\end{cases}
$$

In the field of mechanics and vehicle engineering, $a$ and $b$ depend on the way of experience extend coefficient. $b$ is set to 1.1 times of $a$.

Supposed the strength and stress of rear drive axle house bears is distributed normally, and then the fuzzy reliable probability density function can be expressed as:

$$
f(y)=\frac{1}{\beta \sqrt{2 \pi}} \exp \left[-\frac{(y-\alpha)}{2 \beta^{2}}\right]
$$

In (9), $\alpha$ and $\beta$ are the expected value and standard deviation of safety state function of rear drive axle house. Combined (6), (7) and (9), finally fuzzy reliability function of rear drive axle house is obtained:

$$
\begin{aligned}
& R=\int_{a}^{b}\left(\frac{y-a}{b-a}\right)^{2} \cdot \frac{1}{\beta \sqrt{2 \pi}} \exp \left[-\frac{(y-\alpha)}{2 \beta^{2}}\right] d y \\
& +\int_{b}^{+\infty} \frac{1}{\beta \sqrt{2 \pi}} \exp \left[-\frac{(y-\alpha)}{2 \beta^{2}}\right] d y .
\end{aligned}
$$

\section{B. Robustness Reliability Design Method of Rear Drive Axle House}

To avoid the undesired changes when optimizing target function, the sensitivity of target function under restriction conditions need to be minimized. Supposed that $g(\mathbf{Y})$ is target function, $\mathbf{Y}=\left[y_{1}, y_{2}, \ldots, y_{n}\right]^{T}$ are design variables, then the sensitivity of $g(\mathbf{Y})$ is $\left|d g(\mathbf{Y}) / d y_{i}\right| \rightarrow \min$, which need to be minimized. That is, target function is insensitive to the uncertain variables, finally the robustness optimal design is actualized.

\section{MAthematical Modeling of ReAR DRIVE AXLE HOUSE BASED ON MULTI-OBJECTIVE FUZZY RELIABILITY ROBUSTNESS DESIGN METHOD}

Since fuzzy reliability analysis method discusses the randomness and fuzziness of component's force state, while robustness optimal design analysis considers the sensitivity of target function. In this paper, both two methods are used together.

\section{A. Design Variables and Target Functions}

Set up the target function $X$ based on the small tube inner radius $D_{2}$ and thickness $I$ of rear drive axle house:

$$
X=\left[x_{1}, x_{2}\right]=\left[D_{2}, I\right]
$$

Mass of rear drive axle house is required to be minimized, which is equated with minimal volume since the density is constant. To calculate the volume of rear drive axle house approximately:

$$
f_{1}(x)=\pi\left(D_{1} L_{1}+D_{2} L_{2}\right) I+\frac{\pi I L_{3}^{2}\left(D_{2}+D_{3}\right)}{4\left(D_{3}-D_{2}\right) \sin ^{2} \theta} .
$$

In (12), $\theta$ is the angle between inclined plane and end face of conical tube. Take the minimal sensitivity of design variables to the reliability of rear drive axle house as the aim,

$$
f_{2}(X)=\sqrt{\sum_{i=1}^{2}\left[\frac{\partial R}{\partial x_{i}}\right]}
$$




\section{B. Constraint Conditions}

\section{1) Deflection constraint}

The rear drive axle house is mainly supported by small tube, and then the deflection of small tube is required to be less than the allowable range:

$$
g_{1}(X)=\frac{F_{Z}}{48 E I_{y}} L_{2}^{3}-[y]
$$

In (14), $E$ is elastic modulus of rear drive axle house, $I_{y}$ is inertia moment of section, $[y]$ is the allowable deflection.

\section{2) Static strength constraint}

Instantaneous impact load will bring about the damage of rear drive axle house, and then the static strength need to be checked, the reliability constraint of static strength is computed as

$$
g_{2}(X)=R_{S 0}-R_{S} \leq 0 \text {. }
$$

In (15), $R_{S}$ is the reliability function of static strength, $R_{S 0}$ is the given reliability of static strength. Using variation coefficient method to calculate the mean value and standard deviation of stress:

$$
\bar{\sigma}_{S}=\frac{32 \bar{K} \bar{L} \overline{F_{Z}^{\prime}}\left(D_{2}+2 I\right)}{\pi\left[\left(D_{2}+2 I\right)^{4}-D_{2}^{4}\right]} .
$$

Variation coefficient and standard deviation are calculated respectively as in (17).

$$
V_{S}=\left[V_{k}^{2}+V_{L}^{2}+V_{F_{Z}^{\prime}}^{2}\right]^{0.5}, \quad S_{\sigma_{S}}=V_{S} \overline{\sigma_{S}}
$$

In (16) and (17), $F_{Z}^{\prime}$ is momentary excessive impact load, $\overline{F^{\prime}}$ is the average value of momentary excessive impact load, $L$ is the distance between critical section and reduce house, $V_{k}, V_{L}$ and $V_{F}$ are variation coefficients of $k, L$ and $F_{Z}^{\prime}$ respectively.

\section{3) Fatigue strength constraint}

Tractor's roads are rather tricky, affected by alternate impart load, rear drive axle house is required to experience quite a long time. Since stress concentration factor at the juncture of small tube and big tube only affects the amplitude of stress, has no effect on average stress, the reliability constraint of fatigue strength is computed as

$$
g_{3}(X)=R_{H 0}-R_{H} \leq 0 \text {. }
$$

In (18), $R_{H}$ is the reliability function of fatigue strength of rear drive axle house, $R_{H 0}$ is the given reliability of fatigue strength of rear drive axle house.

$$
\bar{\sigma}_{S}=\frac{32 \bar{K} \bar{L} \overline{F_{Z}^{\prime \prime}}\left(D_{2}+2 I\right)}{\pi\left[\left(D_{2}+2 I\right)^{4}-D_{2}^{4}\right]} .
$$

$F^{\prime \prime}$ denotes alternate load. Variation coefficient and standard deviation are calculated respectively as in (20):

$$
V_{H}=\left[V_{k}^{2}+V_{L}^{2}+V_{F_{Z}}^{2}\right]^{0.5}, \quad S_{\sigma_{H}}=V_{H} \overline{\sigma_{H}} .
$$

\section{4) Dimension constraint}

The diameter of big tube on rear drive axle house is required to be bigger than that of small tube,

$$
g_{4}(X)=D_{2}-D_{1} \leq 0 \text {. }
$$

5) Fuzzy boundary condition constraint of variable $X$

To confirm the selected range of variable $X$ according to experience. Supposed $\underline{x}_{i}$ and $\overline{x_{i}}$ are the lower and upper bounds of variable $x_{i}, i=1,2$, the range of thickness of rear drive axle house is between $8 \mathrm{~mm}$ and $22 \mathrm{~mm}$, the range of small tube diameter is between $80 \mathrm{~mm}$ and $200 \mathrm{~mm}$.

\section{Solution of Model}

Genetic algorithm (GA) is an efficient, concurrent, robust and global optimization method based on Darwin's theory and Mendel's law. GA is widely applied in engineering optimization, graphic processing and artificial life etc. GA is applied for optimal design of rear drive axle house in this paper. Linear membership functions are used to construct target functions, design variables and membership functions of constraint functions. Performance constraint membership function $\mu_{G j}(y)$ is defined as:

$$
\mu_{G j}(y)= \begin{cases}1 & \left(g_{j}(y) \leq b_{j}\right) \\ \frac{\left(b_{j}+d_{j}\right)-g_{j}(y)}{b_{j}} & \left(b_{j}<g_{j}(y)<b_{j}+d_{j}\right) . \\ 0 & \left(g_{j}(y) \geq b_{j}+d_{j}\right)\end{cases}
$$

In (22), $g_{i}(y)$ is the $j$ th constraint function, $b_{j}$ and $d_{j}$ are the lower and upper boundary of the $j$ th constraint function respectively. Variable constraint membership function $\mu_{\sim_{j}}$ is defined as

$$
\mu_{-j}= \begin{cases}1 & \left(y_{j}^{1}<y_{j}<y_{j}^{u}\right) \\ 1-\frac{y_{j}-y_{j}^{u}}{d_{j}^{u}} & \left(y_{j}^{u} \leq y_{j} \leq y_{j}^{u}+d_{j}^{u}\right) \\ 1+\frac{y_{j}-y_{j}^{1}}{d_{j}^{1}} & \left(y_{j}^{1}-d_{j}^{1} \leq y_{j} \leq y_{j}^{1}\right) \\ 0 & \left(y_{j}>y_{j}^{1}+d_{j}^{u} \& y_{j}<y_{j}^{1}-d_{j}^{1}\right)\end{cases}
$$


In (23), $y_{j}$ is the $j$ th design variable, $\underset{\sim_{j}}{\mu_{j}}$ is membership function of the $j$ th variable, $d_{j}^{1}$ and $y_{j}^{1}$ are the lower and upper boundary of $\mu_{\sim_{j}}$ on ascending segment, while $d_{j}^{u}$ and $y_{j}^{u}$ are the lower and upper boundary of $\mu_{\sim_{j}}$ on descending segment. The membership function of fuzzy target $F_{i}$ of all the sub-objective functions $\mu_{F_{i}}(y)$ is defined as

$$
\mu_{F_{i}}(y)= \begin{cases}1 & \left(f_{i}(y) \leq f_{i}^{\min }\right) \\ \frac{f_{i}^{\max }-f_{i}(y)}{f_{i}^{\max }-f_{i}^{\min }} & \left(f_{i}^{\min }<f_{i}(y)<f_{i}^{\max }\right) . \\ 0 & \left(f_{i}(y) \geq f_{i}^{\max }\right)\end{cases}
$$

In (24), $f_{i}(y)$ is the $i$ th target function, $f_{i}^{\min }$ and $f_{i}^{\max }$ are the lower and upper boundary of the $i$ th target function. The membership functions of fuzzy constraints and target functions can be obtained by combined solving (22) (24), simultaneously, the maximal value $M_{k}$ and minimal value $m_{k}$ of all sub-objective functions can also be found using MATLAB optimization toolbox. Finally, fuzzify all the single-target functions using (25).

$$
\mu_{f_{k}}(y)=\sqrt{\frac{M_{k}-f_{k}(y)}{M_{k}-m_{k}}}(k=1,2) .
$$

Though computing the superior set membership functions of multi-target optimal functions and the optimal solutions, multi-targets fuzzy optimization problems turn into single-target optimization problem, and the optimization functions are concluded as:

$$
\left\{\begin{array}{l}
\lambda, y \\
\max \lambda \\
\text { s.t. } g_{p}(y) \leq 0 \quad(p=1,2,3,4) . \\
\mu_{f_{k}}(y) \geq \lambda \quad(k=1,2) \\
\lambda \in[0,1]
\end{array}\right.
$$

According to the above calculation method, multitarget fuzzy reliability robustness optimization model is changed into normal single-target optimization model. In addition, using the GA to solve the model, the optimal design parameters of the rear drive axle house is shown in Fig .6. TABLE II. gives out the solutions of fuzzy reliability robustness optimization and the primary design parameters.

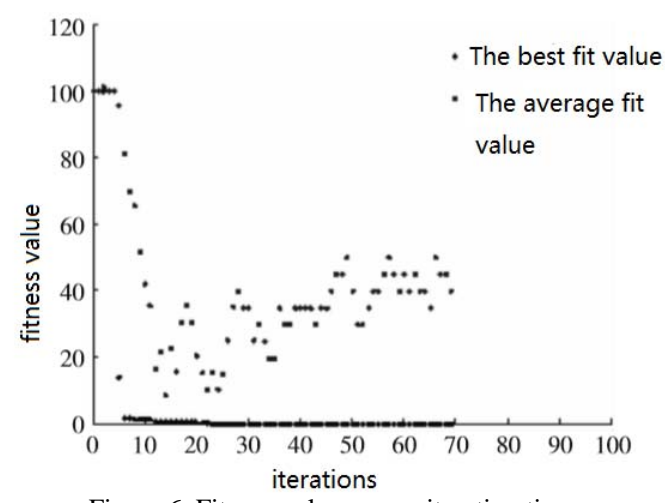

Figure 6. Fitness value versus iteration times

TABLE II. DESIGN PARAMETERS OF REAR DRIVE AXLE HOUSE

\begin{tabular}{|c|c|c|c|c|c|}
\hline $\begin{array}{c}\text { Design } \\
\text { Method }\end{array}$ & $D_{2} / \mathrm{mm}$ & $I / \mathrm{mm}$ & $f_{1}(X) / \mathrm{mm}$ & $f_{2}(X) /(\mathrm{m} / \mathrm{s})$ & $R$ \\
\hline Traditionally & 97 & 12 & $2.20 \times 10^{6}$ & 6.53 & 1.0 \\
\hline $\begin{array}{c}\text { Fuzzy } \\
\text { robust }\end{array}$ & 89 & 10 & $1.75 \times 10^{6}$ & 4.37 & 0.99 \\
\hline
\end{tabular}

After 70 times iteration, the computation program of GA ends, and the solutions converge (convergent condition is that the difference of successive fitness values is less than 0.01).

Compared with the primary design parameters, the optimal parameters reduce the mass of rear drive axle house by $20.45 \%$, lower the sensitivity by $33.08 \%$. Using ANSYS Workbench to analyze the optimal rear drive axle house, the maximal stress of critical section achieves 272 $\mathrm{MPa}$, which is less than the permissible stress $443 \mathrm{MPa}$. Traditionally the maximal stress of critical section is increased by thickening the rear drive axle house, while using the fuzzy reliability robustness optimization method in this paper, the maximal stress is ensured, also the mass reduced. The backup coefficient is 6.2 using hydraulic fatigue machine to check perpendicular bending strength, which meets the national standard. Since the sensitivity reduces, that is the change of design variables is insensitive to the reliability of rear drive axle house, which keeps the tractor performance stable.

\section{CONCLUSIONS}

This paper firstly utilizes UG to build the physical model of rear drive axle house and then applies ANSYS Workbench to do mechanical simulation, finally finds out the location of maximal stress. The whole progress avoids the effects of human factor.

Compared with the traditional design method, the fuzzy reliability robustness optimization design method in this paper has obvious advantages.

Solving the model by GA, the results have excellent robustness, also the results have been successfully adopted in the agricultural machines.

\section{ACKNOWLEDGMENT}

This work is supported by National Natural Science Foundation of China (NO.51305402). 


\section{REFERENCE}

[1] W. Hua Liao, The Finite Element Analysis and Optimization research on rear drive axle house of cars, Changsha: Hunan University, 2009.

[2] S. Yanqing, The Finite Element Analysis and Application on anterior drive axle house of tractor based on ANSYS, Changchun: Jilin University, 2012.

[3] S. Xiaojiang, Q. Feng and Z. Haifeng etc, ANSYS Finite Element Analysis Method and samples analysis, Beijing: China Water Power Press, 2005.

[4] Z. Yimin, L. Renyun and L. Qiaoling, "Reliability robust design optimization of rear axle based on particle swarm optimization," Journal of Mechanical Strength, vol. 29, no. 5, pp. 774-778, 2007.

[5] T. Yingshi, Z. Wu, and D. Xinlin, "The fatigue life analysis and improvement of rear drive axle house based on the dynamics simulation of cars,” Automotive Engineering, vol. 31, no. 2, pp. 114-117, 2009.

[6] S. Zhili, C. Liangyu, Practical mechanical reliability design theory and method, Beijing: Science Press, 2003.
[7] L. Yonghua, H. Weidong, "Robust reliability optimal design of mechanical parts,” Mechanical Design, vol. 26, no. 5, pp.46-48, 2009.

[8] L. Guanghui, L. Taotao, Z. Lihua, "The fuzzy reliability robust design based on MATLAB," Journal of Advanced Materials Research, vol. 479, no. 481, pp. 995-1003, 2012.

[9] P. Lianggui, J. minggang, Mechanical Design, Beijing: Higher Education Press, 2001.

[10] L. Yingjie, Z. Shanwen and L. Xuwu, et al, MATLAB genetic algorithm toolbox and its application, Shanxi: Xidian University Press, 2005.

[11] A. Konak, D. Coit, E. Smith, "Multi-objective optimization using genetic algorithms: a tutorial," Reliability Engineering \& System Safety,vol. 91, pp. 992-1007, 2006

[12] JB / T 8582.1-2001. The drive axle of farm transport vehicles [S] 